\title{
Cardiovascular Risk Factors in Patients with Erectile Dysfunction
}

\author{
Aline Cristine Salum Fernandes Maia1 , Francisco Pedro \\ Pinheiro², José Germano Ferraz de Arruda33, Luis César Fava \\ Spessoto $^{3}$, Pedro Francisco Ferraz de Arruda3, Fernando Nestor \\ Fácio Júnior 4
}

\author{
${ }^{1}$ Health Sciences, Medicine School in São José do Rio Preto (FAMERP), São José do Rio Preto, SP, Brazil \\ ${ }^{2}$ Health Sciences, FAMERP, São José do Rio Preto, SP, Brazil \\ ${ }^{3}$ Urology Department FAMERP, São José do Rio Preto, SP, Brazil \\ ${ }^{4}$ Head of Surgery Department, FAMERP, São José do Rio Preto, SP, Brazil
}

\begin{abstract}
While not lethal, erectile dysfunction (ED) can negatively affect the quality of life of patients. The objective of this study was to investigate cardiovascular risk factors (CRF) associated with ED, taking into account their sociodemographic characteristics. Possible correlations between the degree of ED and CRF were investigated. Fifty-six patients with ED, with ages ranging from 38 to 79 years (mean of $57.4 \pm 8.4$ years), with or without CRF were prospectively studied. ED was classified as mild, moderate or severe using the International Index of Erectile Function (IIEF). Demographic (age, marital status, number of children, education level and place of residence) and clinical data relating to CRF [high blood pressure (hypertension), diabetes, alcoholism, weight and smoking] were obtained by applying a questionnaire. Frequency tables were used to assess the association of the degree of ED with sociodemographic and clinical variables. Most patients were married $(82.1 \%)$ had children $(85.7 \%)$ and incomplete primary education (73.3\%). Moreover, most participants had severe ED (75\%), followed by moderate $(17.9 \%)$ and mild (7.1\%). Hypertension was the most common CRF (53.6\%) followed by diabetes, obesity, alcohol consumption and smoking. No significant association was found when the mean age and body mass index were evaluated in respect to the degree of ED. Moreover, no significant correlation was found for the degree of ED in relation to hypertension, diabetes, smoking and alcohol consumption. Most hypertensive patients and nearly half of the smokers and ex-smokers had grade 3 ED. Grade 3 ED in this study may be related to the high frequency of concomitant CRF associated to ED however there was no significant association between ED in general and CRF.
\end{abstract}

Keywords: erectile dysfunction, risk factors, cardiovascular disease

\begin{abstract}
Introduction
Erectile dysfunction (ED) is defined as the inability to achieve and sufficiently maintain penile erection for satisfactory sexual intercourse (National Institutes of Health, 1993). This dysfunction affects approximately 150 million men worldwide, but there is a projection that more than 300 million patients will be affected by 2025 (Hatzimouratidis et al., 2010). ED is considered an important public health problem with regard to unhealthy living habits (Abdo et al., 2006) that negatively influence the individual's self-esteem (Phé \& Rouprêt, 2012).
\end{abstract}

The risk factors most commonly associated with ED are high blood pressure (hypertension), diabetes mellitus, smoking, excessive alcohol consumption, obesity, prostate diseases, depression, age and socioeconomic factors (Morillo et al., 2002; Nicolosi et al., 2003; Spessoto et al., 2010; Almogbel, 2014; Pinheiro et al., 2015).
About $40 \%$ of men with ED present with cardiovascular disease (Kawanishi et al., 2001; Solomon et al., 2003). Furthermore, it has been demonstrated that ED precedes the onset of cardiovascular disease (CVD) symptoms by approximately three years (Thompson et al., 2005); there is a $23 \%$ higher risk of death due to CVD in patients with ED (Hotaling et al., 2012). 
The evaluation of ED as an early symptom of endothelial dysfunction and atherosclerosis, as a predictor of future cardiovascular events and death, may facilitate the identification of patients at high cardiovascular risk. Thus, the aim of this study was to correlate cardiovascular risk factors (CRF) with the degree of ED taking into account the sociodemographic conditions of patients.

\section{Patients and Methods}

Fifty-six patients with ED, with or without CRF were prospectively investigated in a cross-sectional, quasirandomized (in order of arrival) study, regardless of ethnical background. All patients, residents in the region of São José do Rio Preto, SP, Brazil, were evaluated from September 2013 to December 2014. This study was approved by the Research Ethics Committee of the Medicine School in Sao Jose do Rio Preto (FAMERP).

Patients were treated at the Urology Clinic of the teaching hospital of FAMERP. Subjects transferred to other clinics, presenting with morbid obesity or a physical disability and those who were under 18 years old were excluded. All patients complaining of ED were included after they completed a questionnaire on erectile function, the International Index of Erectile Function 5 (IIEF-5), which consists of five questions covering areas of male sexual function corresponding to the erection, orgasm and to sexual desire (Rosen et al., 1999). When the score of the IIEF-5 is between 17 and 24, the ED is classified as mild (grade 1), between 10 and 16, the ED is moderate (grade 2) and when less than 10 points the ED is considered severe (grade 3 ).

Sociodemographic data (age, marital status, number of children, education level and place of residence) and related clinical CRF [hypertension, diabetes, alcoholism, body mass index (BMI) and smoking] were obtained by applying a second questionnaire. Alcoholism was characterized in patients who drank alcoholic beverages every day.

All patients were weighed on digital weighing scales (Glass 6 FW G-Tech) and their height was measured using a tape measure. Weight was classified according to the BMI, which is calculated by dividing weight (in kilograms) by the square of the height (in meters). A BMI of from 18.5 to $24.9 \mathrm{~kg} / \mathrm{m}^{2}$ is considered normal weight, between 25.0 and 29.9 $\mathrm{kg} / \mathrm{m}^{2}$ is considered overweight, from 30.0 to 34.9 $\mathrm{kg} / \mathrm{m}^{2}$ is class 1 obesity, 35.0 to $39.5 \mathrm{~kg} / \mathrm{m}^{2}$ is class 2 obesity and a BMI of more than $40.0 \mathrm{~kg} / \mathrm{m}^{2}$ is classified as class 3 obesity.

Descriptive statistics (mean, standard deviation, median, minimum and maximum) were used for data analysis. Quantitative variables were compared using the $\mathrm{t}$ test for independent samples or the KruskalWallis test (nonparametric). Frequency tables were used to identify any associations of the degree of ED (mild, moderate and severe) with sociodemographic (age, marital status, number of children, education level and place of residence) and CRF variables (hypertension, diabetes, alcohol consumption, BMI and smoking). All analyzes were performed using the R-64 computer software version 2.13.0 (The R Foundation for Statistical Computing, Auckland, New Zealand). The level of significance was set for an alpha error greater than 0.05 .

\section{Results}

The ages of patients ranged from 38 to 79 years (57.4 \pm 8.4 years $), 46(82.1 \%)$ patients were married, seven $(12.5 \%)$ were divorced and three $(5.4 \%)$ were single. Of the patients studied, $85.7 \%$ had from one to seven children (mean: $2.8 \pm 1.3$ children). The most common level of education was incomplete primary education $(n=41-73.3 \%)$ followed by complete primary schooling $(\mathrm{n}=7-12.5 \%)$, complete secondary education ( $\mathrm{n}=5-8.9 \%)$, incomplete secondary education $(\mathrm{n}=2-3.5 \%)$ and university degree $(n=1-1.8 \%)$. Most patients $(62.5 \%)$ resided in the region surrounding São José do Rio Preto with the rest $(37.5 \%)$ living in the city of São José do Rio Preto itself.

The most frequent degree of ED was severe $(n=42$ $75 \%)$, followed by moderate $(n=10-17.9 \%)$ and mild ( $\mathrm{n}=4-7.1 \%)$.

The most frequent cardiovascular risk factor (Table 1) was hypertension $(53.6 \%)$ and $44.6 \%$ of the patients with ED were obese. A total of $41.1 \%$ of the patients were smokers $(8.9 \%)$ or ex-smokers $(32.2 \%)$. 
Table 1 - Distribution of cardiovascular risk factors in patients with erectile dysfunction $(\mathrm{n}=56)$.

\begin{tabular}{lll}
\hline Risk factor & $\mathrm{n}$ & $\%$ \\
\hline Hypertension & 30 & 53.6 \\
Diabetes & 29 & 51.8 \\
Alcoholism & 24 & 42.9 \\
Body mass index & & \\
$\quad$ Normal & 12 & 21.4 \\
$\quad$ Overweight & 19 & 33.9 \\
$\quad$ Obese & 25 & 44.6 \\
$\quad$ Smoking & & \\
$\quad$ Ex-smoker & 18 & 32.2 \\
$\quad$ Smoker & 5 & 8.9 \\
$\quad$ Non-smoker & 33 & 58.9 \\
\hline
\end{tabular}

Regarding age, Table 2 shows that the age ranged from 38.0 to 79.0 years, with a higher mean age for patients with grade 3 ED.

Table 2 - Degree of erectile dysfunction (ED) by age

\begin{tabular}{llllll}
\hline Degree of ED & \multicolumn{2}{l}{ Age (years) } & \\
& Mean & SD & Median & Min & Max \\
\hline 1 & 50.5 & 5.0 & 50.0 & 45.0 & 57.0 \\
2 & 57.4 & 6.7 & 56.0 & 49.0 & 71.0 \\
3 & 58.1 & 8.9 & 57.0 & 38.0 & 79.0 \\
\hline
\end{tabular}

$\mathrm{SD}=$ standard deviation $;$ Min = minimum; $\mathrm{Max}=$ maximum

There was no significant association between the mean age of patients and the degree of ED (p-value $=0.25)($ Table 3).

Table 3 - Comparison between age and degree of erectile dysfunction (ED) using the t test for two independent samples.

\begin{tabular}{|c|c|c|c|c|}
\hline \multirow[t]{2}{*}{ Degree of ED } & \multirow[b]{2}{*}{$\mathrm{n}$} & \multicolumn{2}{|c|}{ Age (years) } & \multirow[t]{2}{*}{ p-value } \\
\hline & & Mean & SD & \\
\hline 1 and 2 & 14 & 55.4 & 6.9 & 0.25 \\
\hline 3 & 42 & 58.1 & 8.9 & \\
\hline
\end{tabular}

$\mathrm{SD}=$ standard deviation

In Table 4, the mean BMI of patients with grades 1 and 3 ED was classified as obesity class $1\left(30.0\right.$ to $\left.34.9 \mathrm{~kg} / \mathrm{m}^{2}\right)$ while for patients with grade $2 \mathrm{ED}$, the mean BMI was considered overweight $\left(25.0\right.$ to $\left.29.9 \mathrm{~kg} / \mathrm{m}^{2}\right)$.

Table 4 - Comparison of the degree of erectile dysfunction (ED) in respect to the body mass index $(B M I)(n=56)$.

\begin{tabular}{llllll}
\hline Degree of ED & $\begin{array}{l}\text { BMI } \\
\text { Mean }\end{array}$ & SD & Median & Min & Max \\
\hline 1 & 31.6 & 8.4 & 31.0 & 22.8 & 41.5 \\
2 & 28.5 & 3.9 & 29.2 & 23.2 & 34.0 \\
3 & 30.9 & 5.5 & 30.4 & 19.4 & 43.3 \\
\hline \multicolumn{5}{l}{ SD = standard deviation; Min = minimum; Max = maximum }
\end{tabular}

There was no significant association between the mean BMI and the degree of ED (p-value $=0.37)($ Table 5). 
Table 5 - Body mass index $\left(\mathrm{kg} / \mathrm{m}^{2}\right)$ and degree of erectile dysfunction (ED) using the $\mathrm{t}$ test for two independent samples.

\begin{tabular}{lllll}
\hline Degree of ED & \multicolumn{4}{l}{ Body mass index } \\
& $\mathrm{n}$ & Mean & SD & p-value \\
\hline 1 and 2 & 14 & 29.3 & 5.4 & 0.37 \\
3 & 42 & 30.9 & 5.5 & \\
\hline \multicolumn{2}{l}{ SD = standard deviation } &
\end{tabular}

There was no significant association between the median number of children and the degree of ED ( $p$-value $=0.99$; Kruskal-Wallis test), with a median of 2.5 children both for patients with grades 1 and 2 ED and for those with grade 3 ED. Moreover there was no association between the degree of ED and having children or not ( $\mathrm{p}$-value = 1.0; Fisher's exact test).

No significant correlation was found in an analysis of the CRF (hypertension, diabetes, smoking and alcoholism) and ED (p-value > 0.05; Pearson chi-square) (Tables 6 and 7).

Table 6 - Comparison between mild (grade 1), moderate (grade 2) and severe (grade 3) erectile dysfunction in respect to hypertension, diabetes and alcoholism.

\begin{tabular}{lllll}
\hline Degree of ED & Hypertensive & Non-hypertensive & Total & p-value \\
\hline 1 and 2 & 71.4 & 28.6 & 25.0 & \\
3 & 47.6 & 52.4 & 75.0 & 0.122 \\
Total & 100 & 100 & 100 & \\
\hline Degree of ED & Diabetic & Non-diabetic & Total & p-value \\
\hline 1 and 2 & 50.0 & 50.0 & 25.0 & \\
3 & 52.4 & 47.6 & 75.0 & 0.877 \\
Total & 100 & 100 & 100 & \\
\hline Degree of ED & Alcoholic & Non-alcoholic & Total & p-value \\
\hline 1 and 2 & 42.9 & 57.1 & 25.0 & 1.000 \\
3 & 42.9 & 57.1 & 75.0 & \\
Total & 100 & 100 & 100 & \\
\hline \multicolumn{5}{c}{ Hypertension: Pearson qui-squared $=2.393 ;$ GL $=1$} \\
& Diabetes: Pearson qui-squared $=0.024 ; \mathrm{GL}=1$ & &
\end{tabular}

Table 7 - Comparison between mild (grade 1), moderate (grade 2) and severe (grade 3) erectile dysfunction in respect to smoking.

\begin{tabular}{llllll}
\hline Degree of ED & Ex-smoker & Non-smoker & Smoker & Total & p-value \\
\hline 1 and 2 & 21.4 & 71.4 & 7.2 & 25.0 & \\
3 & 35.7 & 54.8 & 9.5 & 75.0 & 0.541 \\
Total & 100 & 100 & 100 & 100 & \\
\hline
\end{tabular}

Pearson qui-squared = 1.228; GL $=2 ;$

\section{Discussion}

The present study shows that the most common cardiovascular risk factor in patients with ED was hypertension; these results corroborate data in the literature (Spessoto et al., 2010; Spessoto, 2012). As elevated blood pressure is an independent and continuous risk factor for cardiovascular disease (Lewington et al., 2002), the data suggest that hypertension may influence the onset or worsening of ED.

About half $(51.8 \%)$ of the patients with ED were also diabetics. This finding agrees with data reported in the literature, i.e., the prevalence of diabetes in patients varies between 35 and $85 \%$ (Malavige \&
Levy, 2009; Lopez et al., 2013). On investigating diabetic patients, Almogadel (2014) found that $83 \%$ of patients had ED.

In this study, $78.5 \%$ of patients were overweight, a result that substantiates data in the literature; Walczak et al. (2002) studied 154 men with ED and found that $79 \%$ were overweight. On investigating the impact of obesity on erectile function, Chung et al. (1999) analyzed the erectile capacity of 321 men with ED using Doppler ultrasound of the cavernous arteries of the penis. The authors concluded that the quality of erectile function was better in non-obese rather than in obese patients. 
Regarding the degree of ED, $75 \%(n=42)$ of patients had severe ED with the mean BMI of these patients being categorized as class 1 obesity. This finding is consistent with Veronelli et al. (2006) who, on using the IIEF questionnaire for patients aged 23 and 50, found that the degree of ED was worse in obese individuals.

In the current study, $41.1 \%$ of the patients with ED were smokers or former smokers. Several epidemiological studies have shown that smoking not only increases the risk of ED (Kupelian et al., 2007; Saigal et al., 2006), but also increases the risk be ED associated with other cardiovascular risk factors (hypertension, diabetes and dyslipidemia) or aging (Nicolosi et al. 2003; Bortolotti et al, 2001).

According to Santos et al. (2008), clinical and experimental studies have shown that ED induced by cigarette smoking is associated with a deficiency in penile blood flow and acute vasospasm of the penile arteries. Furthermore, long-term smoking has deleterious effects on the vascular endothelium and peripheral nerves and so not smoking reduces the risk of ED.

Regarding the degree of ED, $45.2 \%$ of patients with grade 3 were smokers or ex-smokers. On investigating 118 former smokers with ED, Pourmand et al. (2004) found that the clinical improvement one year after smoking cessation was lower in older patients and those with severe ED.

In this study, $42.9 \%$ of patients with ED were alcoholics. Lee et al. (2010) and Cheng et al., (2007) evaluated the effect of alcohol intake in 816 individuals and found that alcohol consumption can impair erectile function.

Overall, the evaluation of ED as an early symptom of endothelial dysfunction and atherosclerosis and as a predictor of future cardiovascular events and death can help identify patients at high cardiovascular risk (Lojanapiwat et al., 2009; Böhm et al., 2010; Chew et al., 2008; Montorsi et al., 2009). On the other hand, ED presents no risk of death to the patient by itself but, from a psychological point of view, the negative consequences of this dysfunction have a considerable impact on the quality of life of patients.

The influence of CRF such as obesity, hypertension, diabetes, smoking and alcohol on patients with ED requires further scientific research using larger sample sizes compared to this study. No statistically significant associations between ED and CRF were found in the current series, possibly due to the small number of patients studied.

Another relevant aspect is the clinical importance of the results, as they reinforce the need for a multidisciplinary approach to patients with ED who may have one or more CRF. This multidisciplinary team should include professionals in the fields of medicine, nutrition, physiotherapy, physical education and psychology. Further long-term clinical trials are needed to investigate ED as a marker of cardiovascular diseases.

\section{Conclusion}

There was a predominance of patients with ED in the sixth decade of life, most were married and with a low level of schooling. Hypertension was the most frequent CRF, followed by diabetes, obesity, alcohol consumption and smoking. Most patients with severe ED presented with hypertensive and nearly half were smokers or ex-smokers. Thus, severe ED may be related to the high frequency of concomitant CRF such as hypertension, obesity, smoking, diabetes and alcoholism. However, there was no significant association between ED in general and CRF.

\section{References}

1. Abdo CHN, Oliveira Jr WM, Scanavino MT, Martins FG. Disfunção erétil: resultados do estudo da vida sexual do brasileiro. Rev Assoc Med Bras 2006;52:424-429.

2. Almogbel TA. Erectile dysfunction and other sexual activity dysfunctions among Saudi type 2 diabetic patients. Int J Health Sci (Qassim) 2014;8:347-59.

3. Böhm M, Baumhäkel M, Teo K, Sleight P, Probstfield J, Gao $\mathrm{P}$, et al. Erectile dysfunction predicts cardiovascular events in high-risk patients receiving telmisartan, ramipril, or both: The Ongoing Telmisartan Alone and in combination with Ramipril Global Endpoint Trial/Telmisartan Randomized Assessment Study in ACE intolerant subjects with cardiovascular Disease (ONTARGET/TRANSCEND) Trials. Circulation 2010;121:1439-46.

4. Bortolotti A, Fedele D, Chatenoud L, Colli E, Coscelli C, Landoni $\mathrm{M}$, et al. Cigarette smoking: a risk factor for erectile dysfunction in diabetics. Eur Urol 2001;40:392-6.

5. Cheng JY, Ng EM, Chen RY, Ko JS. Alcohol consumption and erectile dysfunction: meta-analysis of population-based studies. Int J Impot Res 2007;19:343-52.

6. Chew KK, Bremner A, Jamrozik K, Earle C, Stuckey B. Male erectile dysfunction and cardiovascular disease: is there an intimate nexus? J Sex Med 2008;5:928-34.

7. Chung WS, Sohn JH, Park YY. Is obesity an underlying factor in erectile dysfunction? Eur Urol 1999;36:68-70.

8. Hatzimouratidis K, Amar E, Eardley I, Giuliano F, Hatzichristou D, Montorsi F et al. Guidelines on male sexual dysfunction: erectile dysfunction and premature ejaculation. Eur Urol 2010;57:804-14.

9. Hotaling JM, Walsh TJ, Macleod LC, Heckbert S, Pocobelli G, Wessells H, et al. Erectile dysfunction is not independently associated with cardiovascular death: data from the Vitamin and Lifestyle (VITAL) study. J Sex Med 2012;9:2104-10.

10. Kawanishi Y, Lee KS, Kimura K, Koizumi T, Nakatsuji H, Kojima K, et al. Screening of ischemic heart disease with cavernous artery blood flow in erectile dysfunction. Int J Impot Res 2001;13:100-103.

11. Kupelian V, Link CL, McKinlay JB. Association between smoking, passive smoking, and erectile dysfunction: results from the Boston Area Community Health (BACH) survey. Eur Urol 2007;52:416-22.

12. Lee AC, Ho LM, Yip AW, Fan S, Lam TH. The effect of alcohol drinking on erectile dysfunction in Chinese men. Int $\mathrm{J}$ Impot Res 2010;22:272-8.

13. Lewington S, Clarke R, Qizilbash N, Peto R, Collins R, for 
the Prospective Studies Collaboration. Age-specific relevance of usual blood pressure to vascular mortality: a meta-analysis of individual data for one million adults in 61 prospective studies. Lancet 2002;360:1903-13.

14. Lojanapiwat B, Weerusawin T, Kuanprasert S. Erectile dysfunction as a sentinel marker of endothelial dysfunction disease. Singapore Med J 2009;50:698-701.

15. López M CM, Heredia V ME, González HR, Rosales PE. Disfunción eréctil en portadores de diabetes mellitus tipo 2 en edad productiva. Rev Med Chil 2013;141:1555-59.

16. Malavige LS, Levy JC. Erectile dysfunction in diabetes mellitus. J Sex Med 2009;6:1232-47.

17. Montorsi P, Ravagnani PM, Galli S, Ali SG, Briganti A, Salonia A, et al. The triad of endothelial dysfunction, cardiovascular disease, and erectile dysfunction: clinical implications. Eur Urol Suppl 2009;8:58-66.

18. Morillo LE, Díaz J, Estevez E, Costa A, Méndez H, Dávila $\mathrm{H}$, et al. Prevalence of erectile dysfunction in Colombia, Ecuador and Venezuela: a population-based study (DENSA). Int J Impot Res 2002;14 Suppl 2:S10-8.

19. National Institutes of Health Consensus Conference. Impotence. National Institutes of Health Consensus. Development Panel on Impotence. JAMA 1993;270:83-90.

20. Nicolosi A, Moreira ED Jr, Shirai M, Bin Mohd Tambi MI Glasser DB. Epidemiology of erectile dysfunction in four countries: cross-national study of the prevalence and correlates of erectile dysfunction. Urology 2003;61:201-6.

21. Phé V, Rouprêt. M. Erectile dysfunction and diabetes: a review of the current evidence-based medicine and a synthesis of the main available therapies. Diabetes Metab. 2012;38:1-13.

22. Pinheiro FP, Fernandes-Maia ACS, Arruda JGF, Spessoto LCF, Arruda PFF, Facio Jr FN. relationship between sedentary lifestyle and erectile dysfunction. Int $\mathrm{J}$ Sci 2015;4:68-72.
23. Pourmand G, Alidaee MR, Rasuli S, Maleki A, Mehrsai A. Do cigarette smokers with erectile dysfunction benefit from stopping ?: a prospective study. BJU Int 2004;94:1310-3.

24. Rosen RC, Cappelleri JC, Smith MD, Lipsky J, Peña BM. Development and evaluation and of an abridged, 5-item version of the International Index of Erectile Function (IIFE5) as a diagnostic tool for erectile dysfunction. Int J Impot Res 1999;11:319-26.

25. Saigal CS, Wessells H, Pace J, Schonlau M, Wilt TJ Urologic Diseases in America Project. Predictors and prevalence of erectile dysfunction in a racially diverse population. Arch Intern Med 2006;166:207-12.

26. Solomon H, Man JW, Wierzbicki AS, Jackson G. Relation of erectile dysfunction to angiographic coronary artery disease. Am J Cardiol 2003;91:230-1.

27. Spessoto LC, Cordeiro JA, Godoy JM. Effect of systemic arterial pressure on erectile dysfunction in the initial stages of chronic arterial insufficiency. BJU Int 2010;106;1723-5.

28. Spessoto LC. Influência da hipertensão arterial sistêmica e doença arterial periférica em paciente com disfunção erétil. Tese (doutorado). Faculdade de Medicina de São José do Rio Preto. 2012.

29. Thompson IM, Tangen CM, Goodman PJ, Probstfield JL, Moinpour CM, Coltman CA. Erectile dysfunction and subsequent cardiovascular disease. JAMA 2005;294:29963002 .

30. Tostes RC, Carneiro FS, Lee AJ, Giachini FR, Leite R, Osawa Y, et al. Cigarette smoking and erectile dysfunction: focus on NO bioavailability and ROS generation. J Sex Med 2008;5:1284-95.

31. Veronelli A, Masu A, Ranieri R, Rognoni C, Laneri M, Pontiroli AE. Prevalence of erectile dysfunction in thyroid disorders: comparison with control subjects and with obese and diabetic patients. Int J Impot Res 2006;18:111-4.

32. Walczak MK, Lokhandwala N, Hodge MB, Guay AT. Prevalence of cardiovascular risk factors in erectile dysfunction. J Gend Specif Med 2002;5:19-24. 